\title{
A new protocol using acidification for preserving DMSP in macroalgae and comparison with existing protocols
}

\author{
Bucciarelli Eva ${ }^{1,}{ }^{*}$, Stiger-Pouvreau Valerie ${ }^{1}$, Connan Solène ${ }^{1}$
}

${ }^{1}$ Univ Brest CNRS IRD, Ifremer, LEMAR F-29280 Plouzane, France

*Corresponding author : Eva Bucciarelli, email address : Eva.Bucciarelli@univ-brest.fr

\begin{abstract}
:
Dimethylsulfoniopropionate (DMSP) plays many important physiological and ecological roles in macroalgae. The most common method to measure DMSP is by gas chromatography analysis of the dimethylsulfide (DMS) produced after $\mathrm{NaOH}$ hydrolysis $(\mathrm{pH}>12)$. Storage of DMS, however, is not recommended for more than a week. We investigated if acidification can be a suitable method to preserve DMSP in macroalgal samples over three months of storage, compared to widely used protocols such as drying and freezing at $-20^{\circ} \mathrm{C}$. The DMSP content of green (Ulva sp. and Ulva compressa), red (Chondrus crispus) and brown (Bifurcaria bifurcata) macroalgae were analyzed $24 \mathrm{~h}$ after $\mathrm{NaOH}$ addition (control values); and after acidification $(0.2 \mathrm{~mol} \cdot \mathrm{L} \mathrm{HCl}-1)$ for $24 \mathrm{~h}$ of fresh material, followed by $\mathrm{NaOH}$ addition for $24 \mathrm{~h}$. These values were compared to measurements after 3-month storage of samples that had been either dried in a heater $\left(60^{\circ} \mathrm{C}\right.$ for a night, and storage at room temperature), or frozen at $-20^{\circ} \mathrm{C}$, or kept in $0.2 \mathrm{~mol} \cdot \mathrm{L} \mathrm{HCl}-1$. There was no significant difference between DMSP measurements on freshly collected material and after acidification of the samples, whether $24 \mathrm{~h}$ later or after 3 months of storage. This was in contrast with 3-month storage protocols involving overnight drying at $60^{\circ} \mathrm{C}(75-98 \% \mathrm{DMSP}$ loss $)$, and to a lesser degree freezing at $-20^{\circ} \mathrm{C}(37-80 \%$ DMSP loss). We thus advise to acidify macroalgal samples for preservation over long periods of time rather than drying or freezing, when assaying DMSP content.
\end{abstract}

Keywords : acidification, DMSP, drying, freezing, macroalgae, storage protocol 
39 Abbreviations list: DMS, dimethylsulfide; DMSP, dimethylsulfoniopropionate; FW, fresh weight;

40 GC, gas chromatography

This article is protected by copyright. All rights reserved 
Dimethylsulfoniopropionate (DMSP) is a tertiary sulfonium compound produced intracellularly

42 mainly by micro- and macroalgae (Malin and Kirst 1997, Bullock et al. 2017). It plays a wide

43 range of physiological and ecological roles in macroalgae. Within the cells, it serves as an osmolyte, and as an antioxidant (Stefels 2000, Van Alstyne 2008, Rix et al. 2012). DMSP and its enzymatic breakdown product dimethylsulfide (DMS) are also known to play a key role in

46 chemical signalling, from bacteria (Barak-Gavish et al. 2018) to top predators (Nevitt 2011).

47 Recent studies showed that DMSP from macroalgae can either inhibit (Saha et al. 2012) or

48 promote (Kessler et al. 2018) bacterial activity. This production is thought to be part of an 49 activated defense system (Van Alstyne et al. 2001, Wiesemeier et al. 2007), and to induce a food50 source chemical signal for bacteria, that in turn allow the morphogenesis and development of the DMSP-producer macroalga (Kessler et al. 2018, Wichard and Beemelmanns 2018). High DMSP concentrations are generally found in green macroalgae and a few red algal species, while brown macroalgae only contain small amounts (Reed 1983, Van Alstyne and Puglisi 2007).

54 The most common method to measure DMSP is by GC analysis of the DMS released after $24 \mathrm{~h}$ 55 of $\mathrm{NaOH}$ hydrolysis $(\mathrm{pH}>12$; White 1982). However, DMS is a volatile compound, prone to 56 oxidation, that has been shown to decrease significantly in sealed vials after a week of storage 57 (Curran et al. 1998). Besides, other dimethylsulfonium compounds than DMSP can yield DMS 58 after prolonged $\mathrm{NaOH}$ hydrolysis (Howard and Russell 1996). Protocols to preserve the samples 59 of macroalgae and plants have been proposed, including drying or freezing (Karsten et al. 1994, 60 Russell and Howard 1996, McFarlin and Alber 2013, Borges and Champenois 2017). These 61 methods, however, can strongly affect DMSP contents, compared to analyses on fresh samples 62 (Bischoff et al. 1994, Karsten et al. 1994, Russell and Howard 1996). Still, storing samples over 63 more than a week can be unavoidable in case of a cruise or field sampling, or when needing to 64 analyze more than a few samples at a time. Acidification is an alternative method, which has 65 been successfully used to preserve DMSP in seawater and phytoplankton culture samples over 66 months of storage (Curran et al. 1998, del Valle et al. 2011). DMSP is highly stable in low pH

67 solutions (Dacey and Blough 1987). Furthermore, acidification lyses membranes of macroalgal

68 cells and increases their porosity (Zemke-White et al. 1999, 2000), thereby increasing the

69 potential recovery and stabilisation of intracellular DMSP in macroalgae.

70 In this study, we investigated if acidification can be a suitable method to preserve DMSP over 3 months in samples of macroalgae, compared to drying and freezing.

72 Four species of macroalgae were collected by hand at low tide on the west coast of Brittany 73 (Pointe du Diable, $48^{\circ} 28.871^{\prime} \mathrm{N}, 4^{\circ} 46.142^{\prime} \mathrm{W}$ ), a field site nearby the laboratory. These macroalgae include two green, a brown and a red species, to test for the validity of our protocols

This article is protected by copyright. All rights reserved 
on macroalgae with high (green species) and low (red and brown species) DMSP contents (Reed 1983, Van Alstyne and Puglisi 2007). Our green species include the foliose Ulva sp. Linnaeus (collected on Oct. $8^{\text {th }}$ 2018; Chlorophyta, Ulvophyceae, Ulvales, Ulvaceae) and the tubular Ulva compressa Linnaeus (collected on April $8^{\text {th }}$ 2019; Chlorophyta, Ulvophyceae, Ulvales, Ulvaceae). The brown and red species were Bifurcaria bifurcata (collected on Oct. $8^{\text {th }}$ 2018; Ochrophyta, Phaeophyceae, Fucales, Sargassaceae), and Chondrus crispus (collected on Nov. $7^{\text {th }} 2018$; Rhodophyta, Florideophyceae, Gigartinales, Gigartinaceae), respectively. Ten different thalli (i.e., individuals) per species were transported back to the laboratory in plastic bags. Shortly after returning to the laboratory, each individual was carefully dried with a tissue and most of the visible epiphytes (e.g., Ceramiales and Ulvales) were removed by hand. According to the DMSP values expected from the literature, and to ensure that measurements using GC would be detectable, a few micrograms (green macroalgae) to a few milligrams (red and brown macroalgae) from each individual was sampled using a clean scissor. This was repeated 5 times on each individual, so as to have 5 subsets of 10 replicates for the five different protocols. For the first protocol, the samples were placed in $10 \mathrm{~mL}$ glass vials, $5 \mathrm{~mL}$ of $5 \mathrm{~mol} \cdot \mathrm{L} \mathrm{NaOH}^{-1}$ were added and the vials were sealed. DMS resulting from DMSP degradation in these basic conditions $(\mathrm{pH}>12)$ was measured on the following day (Protocol $\mathrm{P} 1-\mathrm{NaOH}-\mathrm{T} 0$ ) and this value was considered as the reference value. Samples from the second subset were wrapped in aluminium foil and dried in a heater at $60^{\circ} \mathrm{C}$ for a night (Protocol P2-Drying), and further kept at room temperature for 3 months. Samples from the third subset were placed in $10 \mathrm{~mL}$ glass vials that were sealed and stored at $-20^{\circ} \mathrm{C}$ for 3 months (Protocol P3-Freezing). Samples from the fourth and the fifth subsets were placed in $10 \mathrm{~mL}$ glass vials with $4 \mathrm{~mL}$ of $0.2 \mathrm{~mol} \cdot \mathrm{L} \mathrm{HCl}^{-1}(\mathrm{pH}$ $<2$ ) and the vials were sealed and kept at room temperature. A day later, the vials of the fourth subset were opened for addition of $1 \mathrm{~mL}$ of $5 \mathrm{~mol} \cdot \mathrm{L} \mathrm{NaOH}^{-1}(\mathrm{pH}>12)$ and the vials were sealed again; DMS analyses were run on the following day (Protocol P4-HCl-T0). Vials of the fifth subset were stored for 3 months (Protocol P5-HCl-Tf). After 3 months, dried samples from Protocol P2-Drying were placed in $10 \mathrm{~mL}$ glass vials, and $5 \mathrm{~mol} \cdot \mathrm{L} \mathrm{NaOH}^{-1}$ was added to all samples from P2-Drying ( $5 \mathrm{~mL})$, P3-Freezing ( $5 \mathrm{~mL})$ and P5-HCl-Tf $(1 \mathrm{~mL})$ so as to achieve a final volume of $5 \mathrm{~mL}$ in the vials. Analyses for DMS were run on the following day. DMSP was analyzed as DMS using a Shimadzu 2010-Plus Gas Chromatograph (GC) equipped with a sulfur-selective flame photometric detector (air $/ \mathrm{H}_{2}: 70 \mathrm{~mL} \cdot \mathrm{min}^{-1} / 60 \mathrm{~mL} \cdot \mathrm{min}^{-1}$ ) and an Equity 1 capillary column $\left(3.2 \mathrm{~mm}\right.$ i.d., $30 \mathrm{~m}$ long, Supelco, $\mathrm{T}=180^{\circ} \mathrm{C}$, carrier gas: $\mathrm{He}, 6.7 \mathrm{~mL}$. $\left.\min ^{-1}\right)$. Detector and injection port temperatures were set at $250^{\circ} \mathrm{C}$. Depending on the macroalgal DMSP content, 10 to $250 \mu \mathrm{L}$ were collected from the headspace of the vials using a gas tight 
syringe and were directly injected into the GC injector port. The same headspace volume was

110 sampled from the DMSP standards and the samples. Calibration curves for protocols $\mathrm{P} 1-\mathrm{NaOH}-$

111 T0, P2-Drying and P3-Freezing consisted in increasing additions of $10^{-3} \mathrm{~mol} \cdot \mathrm{L} \mathrm{DMSP}^{-1}$ into 5

$112 \mathrm{~mL}$ of $5 \mathrm{~mol} \cdot \mathrm{L} \mathrm{NaOH}^{-1}$ in $10 \mathrm{~mL}$ glass vials, which were sealed for a day before analyses.

113 Calibration curves for protocols P4-HCl-T0 and P5-HCl-Tf consisted in increasing additions of

$11410^{-3} \mathrm{~mol} \cdot \mathrm{L} \mathrm{DMSP}^{-1}$ into $4 \mathrm{~mL}$ of $0.2 \mathrm{~mol} \cdot \mathrm{L} \mathrm{HCl}^{-1}$ in $10 \mathrm{~mL}$ glass vials, which were sealed for a 115 day (P4-HCl-T0) or for 3 months (P5-HCl-Tf). One day before the analyses were run, the vials

116 were opened for addition of $1 \mathrm{~mL}$ of $5 \mathrm{~mol} \cdot \mathrm{L} \mathrm{NaOH}^{-1}$ and re-sealed. Five to ten standards were 117 run for calibration. The correlation coefficients $\mathrm{R}^{2}$ of the calibration curves ranged between 0.984 118 and $0.999(0.998 \pm 0.004$, mean $\pm \mathrm{STD}, \mathrm{n}=17)$.

119 Statistical analyses were performed using R software (version 3.6.3; R Core Team 2020)

120 through the integrated development environment Rstudio (version 1.2.5033; Rstudio Team 2020).

121 DMSP levels measured with Protocol P1-NaOH-T0 were compared among species using a

122 Kruskal Wallis test with a confidence level of 95\% as data did not meet the requirements for

123 parametric tests. Multiple comparisons were performed using the pairwise non-parametric

124 Wilcoxon test. Because the data did not follow a normal distribution (Shapiro-Wilks test, $p$-value

$125<0.05$ for each algal species), the differences in DMSP content among protocols for each

126 macroalgal species were tested using the non-parametric Friedman rank test for data in repeated

127 measurement designs at a confidence level of 95\%. When a statistical difference among protocols

128 was detected, post-hoc pairwise comparisons using a Nemenyi-Wilcoxon test were applied. The

129 effect of epiphytes occurrence on DMSP content was tested using a Kruskal Wallis test. The

130 impact of hexane on the removal of epiphytes and therefore on DMSP content was tested using a 131 Paired t test.

132

133

134

135

136

137

138

Figure 1 displays the mean DMSP concentrations for each macroalgal species according to the different protocols (in $\mu \mathrm{mol} \cdot \mathrm{g}^{-1}$ algal fresh weight (FW) for the two green Ulva spp. and in $\mathrm{nmol} \cdot \mathrm{g} \mathrm{FW}^{-1}$ for the brown and red species). To our knowledge, values of DMSP for Bifurcaria bifurcata are not reported in the literature. For Chondrus crispus and U. compressa, our values of DMSP measured following Protocol P1-NaOH-T0 were similar to values reported previously following a similar protocol (respectively, in $\mathrm{nmol} \cdot \mathrm{g} \mathrm{FW}^{-1}:<50$, Reed 1983; $47 \pm$ 21, Russell and Howard 1996; and in $\mu \mathrm{mol} \cdot \mathrm{g} \mathrm{FW}^{-1}$ : 25.4-39.5, Reed 1983; $20.2 \pm 7.3$, Bischoff et al. 1994; 20, Steinke et al. 1996, see also Table S1 for comparison with available data from the literature for the same species, including other analytical methods than GC). Acidification gave the best results as a preservation method for the four studied species. Values measured after $24 \mathrm{~h}$ acidification (P4-HCl-T0) were not significantly different from values measured according 
143 to $\mathrm{P} 1-\mathrm{NaOH}-\mathrm{T} 0$, including for $U$. compressa (Fig. 1). This last species exhibits the same, high,

144 DMSP-lyase activity as the microalgal Phaeocystis sp. $\left(\sim 10 \mathrm{nmol} \cdot \mathrm{min}^{-1} \cdot \mathrm{mg}^{-1}\right.$ of protein;

145 Steinke et al. 1996). Del Valle et al. (2011) showed that acidification was suitable to preserve

146 DMSP for months in microalgal samples, including samples of single cell Phaeocystis spp., but

147 that a substantial loss of DMSP occurs within a few minutes after acid addition when Phaeocystis

148 spp. are present in the colonial stage. This has been attributed to possible differences in the

149 physico-chemical characteristics of the enzymes or to differences in the cellular location of

150 DMSP and the enzymes between single cell and colonial stages of Phaeocystis life cycle (del

151 Valle et al. 2011). In our study there was no measurable DMSP loss in U. compressa after

152 acidification. We cannot rule out, however, that there might be an effect of acidification in other

153 species that have also been shown to express DMSP-lyase activity (e.g., Nishiguchi and Goff

154 1995, Steinke et al. 1996, van Alstyne and Houser 2003, Garcia-Jimenez et al. 2013). The nature

155 of DMSP-lyases in macroalgae has begun to be unveiled only very recently, and their locations

156 are still unknown (De Clerck et al. 2018). Until their characteristics and functioning are better

157 constrained, we recommend to conduct preliminary tests to assess the validity of the acidification

158 protocol before storage, e.g., by comparing values from P1-NaOH-T0 and P4-HCl-T0.

159 There was no statistical difference in DMSP content between acidified samples analyzed

$16024 \mathrm{~h}$ after sampling (P4-HCl-T0) and after 3 months of acidified storage (P5-HCl-Tf) for any of

161 the four species (Fig. 1). On the contrary, only 2-25\% of DMSP remained in all four macroalgae

162 after overnight drying at $60^{\circ} \mathrm{C}$ and 3 months of storage (P2-Drying; Fig. 1). Bischoff et al.

163 (1994), who oven-dried Ulva compressa for $12 \mathrm{~h}$ at $80^{\circ} \mathrm{C}$, also reported that only $\sim 16 \%$ of

164 DMSP remained after 3-4 months of storage. Freezing at $-20^{\circ} \mathrm{C}$ for 3 months (P3-Freezing) also

165 decreased the initial DMSP content of the macroalgae, but to a lesser extent than P2-Drying (20-

$16663 \%$; Fig. 1). We did not test the effects of freeze-drying of the tissues (e.g., Karsten et al. 1994),

167 or freezing at $-80^{\circ} \mathrm{C}$, which may improve the preservation of DMSP compared to freezing at -

$16820^{\circ} \mathrm{C}$.

169 A high variability could however be noted with the acidification protocol, especially for

170 Bifurcaria bifurcata and Chondrus crispus. Removing obvious outliers for these species (Fig. 1)

171 did not change the statistical results: DMSP levels for protocols P4-HCl-T0, P5-HCl-Tf and P1-

$172 \mathrm{NaOH}-\mathrm{T} 0$ remained higher than for P2-Drying and P3-Freezing (Friedman rank tests; $p$ -

173 value $=2.286 .10^{-5}$ and $1.247 .10^{-5}$ for B. bifurcata and C. crispus, respectively). This high

174 variability may be due to intrathallus variability, and to the presence of epiphytes. In Ulva lactuca

175 (Van Alstyne et al. 2007) and in the brown seaweed Taonia atomaria (Paix et al. 2020), DMSP

176 concentrations are higher at the base of the thallus than in the middle of the thallus or at the

This article is protected by copyright. All rights reserved 
177 edges. For B. bifurcata and C. crispus, we had to mix several pieces of the middle part of the 178 thallus to ensure that there would be enough material to analyze (a few milligrams). This may 179 have increased DMSP variability. Epiphytes can also increase DMSP content in some plant 180 species (Dacey et al. 1994). We carefully removed epiphytes such as other algae from our 181 samples, but other epiphytes like bryozoans were still evident and difficult to remove on some

182 samples of C. crispus. Epiphytic microalgae and bacteria could also affect DMSP measurements 183 (Kessler et al. 2018, Paix et al. 2020). In a supplementary experiment, we collected 20

184 individuals of C. crispus (same site of collection, Feb. $7^{\text {th }} 2019$ ): 10 were colonised by epiphytes 185 (including bryozoans), and 10 were devoid of epiphytes. Each one of the 20 individuals was 186 divided in 2 subsamples. One of them was dipped in hexane for $30 \mathrm{~s}$ to remove microfouling 187 organisms (de Nys et al. 1998) before being processed for DMSP measurements. As a result, we 188 could compare DMSP contents (following Protocol P1-NaOH-T0) between populations with and 189 without visible epiphytes $\left(32 \pm 42 \mathrm{nmol} \cdot \mathrm{g} \mathrm{FW}^{-1}\right.$, mean $\pm \mathrm{STD}, \mathrm{n}=10$, and $7 \pm 6 \mathrm{nmol} \cdot \mathrm{g} \mathrm{FW}^{-1}$, 190 mean \pm STD, $n=10$, respectively), and when populations with and without visible epiphytes were 191 dipped in hexane $\left(53 \pm 94 \mathrm{nmol} \cdot \mathrm{g} \mathrm{FW}^{-1}\right.$, mean $\pm \mathrm{STD}, \mathrm{n}=10$, and $9 \pm 11 \mathrm{nmol} \cdot \mathrm{g} \mathrm{FW}^{-1}$, mean \pm 192 STD, $n=10$, respectively). The removal of fouling organisms by hexane dipping did not change 193 the DMSP measurements, neither for the epiphyte colonised samples (Paired-t-test, $\mathrm{t}_{9}=-1.221, p$ $194=0.253$ ) nor for the others (Paired-t-test, $\mathrm{t}_{9}=-0.684, p=0.511$ ). DMSP contents on the contrary 195 were significantly higher in epiphyte colonised samples than in the others (Kruskal-Wallis, Chi196 Square $\left._{1}=5.491, p=0.019\right)$. The presence of epiphytes such as bryozoans may thus explain at 197 least part of the observed DMSP variability in C. crispus.

198 In conclusion, there was no significant difference between DMSP measurements on 199 freshly collected material (P1-NaOH-T0) and after acidification of the samples, whether $24 \mathrm{~h}$ 200 later (P4-HCl-T0) or after 3 months of storage (P5-HCl-Tf), for any of the species that we 201 considered. This is in contrast with 3-month storage protocols involving overnight drying at $60^{\circ} \mathrm{C}$ 202 (P2-Drying), and to a lesser degree freezing at $-20^{\circ} \mathrm{C}$ (P3-Freezing). We thus advise to use 203 acidification $\left(0.2 \mathrm{~mol} \cdot \mathrm{L} \mathrm{HCl}^{-1}, \mathrm{pH}<2\right)$ for preservation of macroalgal samples over long 204 periods of time rather than drying or freezing at $-20^{\circ} \mathrm{C}$, when assaying DMSP content.

206 ACKNOWLEGEMENTS

207 We acknowledge Flavia Bolloro and Lisa Morin for their help during preliminary experiments.

208 We are grateful to two reviewers for their comments that helped to improve the manuscript. 
210 Barak-Gavish, N., Frada, M.J., Ku, C., Lee, P.A., DiTullio, G.R., Malitsky, S., Aharoni, A., 211 Green, S.J., Rotkopf, R., Kartvelishvily, E., Sheyn, U., Schatz, D. \& Vardi, A. 2018. Bacterial 212 virulence against an oceanic bloom-forming phytoplankter is mediated by algal DMSP. Sci. Adv. 213 4: eaau5716.

214

215 Bischoff, B., Karsten, U., Daniel, C., Kuck, K., Xia, B. \& Wiencke, C. 1994. Preliminary

216 assessment of the $\beta$-dimethylsulfoniopropionate (DMSP) content of macroalgae from the tropical 217 Island of Hainan (People's Republic of China). Aust. J. Mar. Fresh. Res. 45: 1329-36.

219 Borges, A.V. \& Champenois, W. 2017. Preservation protocol for dimethylsulfoniopropionate and 220 dimethylsulfoxide analysis in plant material of the Mediterranean seagrass Posidonia oceanica, 221 and re-evaluation of dimethylsulfoniopropionate leaf content. Aquat. Bot. 143: 8-10.

223 Bullock, H.A., Luo, H. \& Whitman, W.B. 2017. Evolution of dimethylsulfoniopropionate 224 metabolism in marine phytoplankton and bacteria. Front. Microbiol. 8: 637.

226 Curran, M.A.J., Jones, G.B. \& Burton, H. 1998. Spatial distribution of dimethylsulfide and 227 dimethylsulfoniopropionate in the Australasian sector of the Southern Ocean. J. Geophys. Res.

228 103: 16677-89.

230 Dacey, J.W.H. \& Blough, N.V. 1987. Hydroxide decomposition of dimethylsulfoniopropionate to 231 form dimethylsulfide. Geophys. Res. Lett. 14: 1246-9.

232

233 Dacey, J.W.H., King, G.M. \& Lobel, P.S. 1994. Herbivory by reef fishes and the production of 234 dimethylsulfide and acrylic acid. Mar. Ecol. Prog. Ser. 112: 67-74.

236 De Clerck, O., Kao, S.H., Bogaert, K.A., Blomme, J., Foflonker, F., Kwantes, M., Vancaester, E., 237 Vanderstraeten, L., Aydogdu, E., Boesger, J., Califano, G., Charrier, B., Clewes, R., Del Cortona, 238 A., D’Hondt, S., Fernandez-Pozo, N., Gachon, C.M., Hanikenne, M., Lattermann, L., Leliaert, F., 239 Liu, X., Maggs, C.A., Popper, Z.A., Raven, J.A., Van Bel, M., Wilhelmsson, P.K.I., 240 Bhattacharya, D., Coates, J.C., Rensing, S.A., Van Der Straeten, D., Vardi, A., Sterck, L., 
242 of multicellularity from the sea lettuce genome. Curr. Biol. 28: 2921-33.

243

244 del Valle, D.A., Slezak, D., Smith, C.M., Rellinger, A.N., Kieber, D.J. \& Kiene, R.P. 2011.

245 Effect of acidification on preservation of DMSP in seawater and phytoplankton cultures:

246 Evidence for rapid loss and cleavage of DMSP in samples containing Phaeocystis sp. Mar. Chem. 247 124: 57-67.

248

249 de Nys, R., Dworjanyn, S.A. \& Steinberg, P.D. 1998. A new method for determining surface 250 concentrations of marine natural products on seaweeds. Mar. Ecol. Prog. Ser. 162: 79-87.

251

252 Garcia-Jimenez, P., Brito-Romano, O. \& Robaina, R.R. 2013. Production of volatiles by the red 253 seaweed Gelidium arbuscula (Rhodophyta): emission of ethylene and dimethyl sulfide. J. Phycol. 254 49: 661-9.

255

256 Howard, A.G., Russell \& D.W. 1996. An alternative approach to the measurements of $\beta$ 257 dimethylsulfoniopropionate (DMSP) and other precursors of dimethylsulfide. In Kiene, R.P., 258 Visscher, P.T., Keller, M.D. \& Kirst, G.O. [Eds.] Biological and Environmental Chemistry of 259 DMSP and Related Sulfonium Compounds. Plenum Press, New York, pp. 65-73.

260

261 Karsten, U., Kuck, K., Daniel, C., Wiencke, C. \& Kirst, G.O. 1994. A method for complete

262 determination of dimethylsulfoniopropionate (DMSP) in marine macroalgae for different 263 geographical regions. Phycologia 33: 171-6.

264

265 Kessler, R.W., Weiss, A., Kuegler, S., Hermes, C. \& Wichard, T. 2018. Macroalgal-bacterial 266 interactions: Role of dimethylsulfoniopropionate in microbial gardening by Ulva (Chlorophyta).

267 Mol. Ecol. 27: 1808-19.

268

269 Malin, G. \& Kirst, G.O. 1997. Minireview - Algal production of dimethylsulfide and its 270 atmospheric role. J. Phycol. 33: 889-96.

271

This article is protected by copyright. All rights reserved 
272 McFarlin, C.R. \& Alber, M. 2013. Foliar DMSO:DMSP ratio and metal content as indicators of 273 stress in Spartina alterniflora. Mar. Ecol. Prog. Ser. 474: 1-13.

274

275 Nevitt, G.A. 2011. The neuroecology of dimethyl sulfide: A global-climate regulator turned

276 marine infochemical. Integr. Comp. Biol. 51: 819-25.

277

278 Nishiguchi, M.K. \& Goff, L.J. 1995. Isolation, purification, and characterization of DMSP lyase 279 (dirnethylpropiothetin dethiomethylase (4.4.1.3)) from the red alga Polysiphonia paniculata. J. 280 Phycol. 31: 567-74.

281

282 Paix, B., Carriot, N., Barry-Martinet, R., Greff, S., Misson, B., Briand, J.F. \& Culioli, G. 2020. A 283 multi-omics analysis suggests links between the differentiated surface metabolome and epiphytic 284 microbiota along the thallus of a mediterranean seaweed holobiont. Front. Microbiol. 11: 494. 285

286 R Core Team. 2020. R: A language and environment for statistical computing. R Foundation for 287 Statistical Computing, Vienna, Austria. URL https://www.R-project.org/.

288

289 RStudio Team. 2020. RStudio: Integrated Development for R. RStudio, Inc., Boston, MA URL

290 http://www.rstudio.com/

291

292 Reed, R.H. 1983. Measurement and osmotic significance of $\beta$-dimethylsulphoniopropionate in 293 marine macroalgae. Mar. Biol. Lett. 4: 173-81.

294

295 Rix, L.N., Burdett, H.L. \& Kamenos, N.A. 2012. Irradiance-mediated

296 dimethylsulphoniopropionate (DMSP) responses of red coralline algae. Estuar. Coast Shelf S. 96:

$297 \quad 268-72$.

298

299 Russell, D.W. \& Howard, A.G. 1996. The determination of DMSP in marine algae and salt marsh 300 plants. In Kiene, R.P., Visscher, P.T., Keller, M.D. \& Kirst, G.O. [Eds.] Biological and 301 Environmental Chemistry of DMSP and Related Sulfonium Compounds. Plenum Press, New 302 York, pp. 155-163.

This article is protected by copyright. All rights reserved 
304 Saha, M., Rempt, M., Gebser, B., Grueneberg, J., Pohnert, G. \& Weinberger, F. 2012.

305 Dimethylsulphopropionate (DMSP) and proline from the surface of the brown alga Fucus

306 vesiculosus inhibit bacterial attachment. Biofouling 28: 593-604.

307

308 Stefels, J. 2000. Physiological aspects of the production and conversion of DMSP in marine algae

309 and higher plants. J. Sea Res. 43: 183-97.

310

311 Steinhagen, S., Barco, A., Wichard, T. \& Weinberger, F. 2019. Conspecificity of the model

312 organism Ulva mutabilis and Ulva compressa (Ulvophyceae, Chlorophyta). J. Phycol. 55: 25-36.

313

314 Steinke, M., Daniel, C. \& Kirst, G.O. 1996. DMSP lyase in marine macro- and microalgae.

315 Intraspecific differences in cleavage activity. In Kiene, R.P., Visscher, P.T., Keller, M.D. \&

316 Kirst, G.O. [Eds.] Biological and Environmental Chemistry of DMSP and Related Sulfonium

317 Compounds. Plenum Press, New York, pp. 317-324.

318

319 Van Alstyne, K.L. 2008. Ecological and physiological roles of dimethylsulfoniopropionate and

320 its products in marine macroalgae. In Amsler C.D. [Eds.] Algal Chemical Ecology. Springer,

321 Berlin, Heidelberg, pp. 173-194.

322

323 Van Alstyne, K. L. \& Houser, L. T. 2003. Dimethylsulfide release during macroinvertebrate

324 grazing and its role as an activated chemical defense. Mar. Ecol. Prog. Ser. 250: 175-81.

325

326 Van Alstyne, K.L., Koellermeier, L. \& Nelson, T.A. 2007. Spatial variation in

327 dimethylsulfoniopropionate (DMSP) production in Ulva lactuca (Chlorophyta) from the

328 Northeast Pacific. Mar. Biol. 150: 1127-35.

329

330 Van Alstyne, K.L. \& Puglisi, M.P. 2007. DMSP in marine macroalgae and macroinvertebrates:

331 Distribution, function, and ecological impacts. Aquat. Sci. 69: 394-402.

332

This article is protected by copyright. All rights reserved 
334 defense systems in marine macroalgae: evidence for an ecological role for DMSP cleavage. Mar. 335 Ecol. Prog. Ser. 213: 53-65.

336

337 White, R.H. 1982. Analysis of dimethyl sulfonium compounds in marine algae. J. Mar. Res. 40: $338 \quad 529-35$.

339

340 Wichard, T. \& Beemelmanns, C. 2018. Role of chemical mediators in aquatic interactions across 341 the prokaryote-eukaryote boundary. J. Chem. Ecol. 44: 1008-21.

342

343 Wiesemeier, T., Hay, M. \& Pohnert, G. 2007. The potential role of wound-activated volatile 344 release in the chemical defence of the brown alga Dictyota dichotoma: Blend recognition by 345 marine herbivores. Aquat. Sci. 69: 403-12.

346

347 Zemke-White, W.L., Clements, K.D. \& Harris, P.J. 1999. Acid lysis of macroalgae by marine 348 herbivorous fishes: myth or digestive nechanism? J. Exp. Mar. Biol. Ecol. 233: 95-113. 349

350 Zemke-White, W.L., Clements, K.D. \& Harris, P.J. 2000. Acid lysis of macroalgae by marine 351 herbivorous fishes : effects of acid pH on cell wall porosity. J. Exp. Mar. Biol. Ecol. 245: 57-68. 
352 Figure 1: DMSP concentrations in the four macroalgal species according to the five different

353 protocols (in $\mu \mathrm{mol}$ or $\mathrm{nmol} \cdot \mathrm{g}^{-1}$ algal fresh weight depending on the algal species). Significant 354 differences among protocols for each macroalgal species are marked with different letters $(\mathrm{n}=$ 35510 ; Friedman rank test for data in repeated measurement designs with post-hoc Nemenyi356 Wilcoxon tests; $p$-value $<0.05)$.

359 Table S1: DMSP content (in $\mu \mathrm{mol}$ or nmol DMSP $\cdot \mathrm{g}$ of algal $\mathrm{FW}^{-1}$ depending on the algal 360 species) for the four species of macroalgae according to the five different protocols of 361 preservation in our study (see text for detail), and comparison with available data from the 362 literature for the same species (or Ulva lactuca as a foliose Ulva sp.). For this study: mean \pm 363 standard deviation; $\mathrm{n}=10$; for literature data, depending on the available data: range, mean or 364 mean \pm standard deviation. ${ }^{*}=$ Ulva lactuca as a foliose Ulva sp. ${ }^{*}=$ Ulva mutabilis conspecific 365 with Ulva compressa (Steinhagen et al. 2019). 

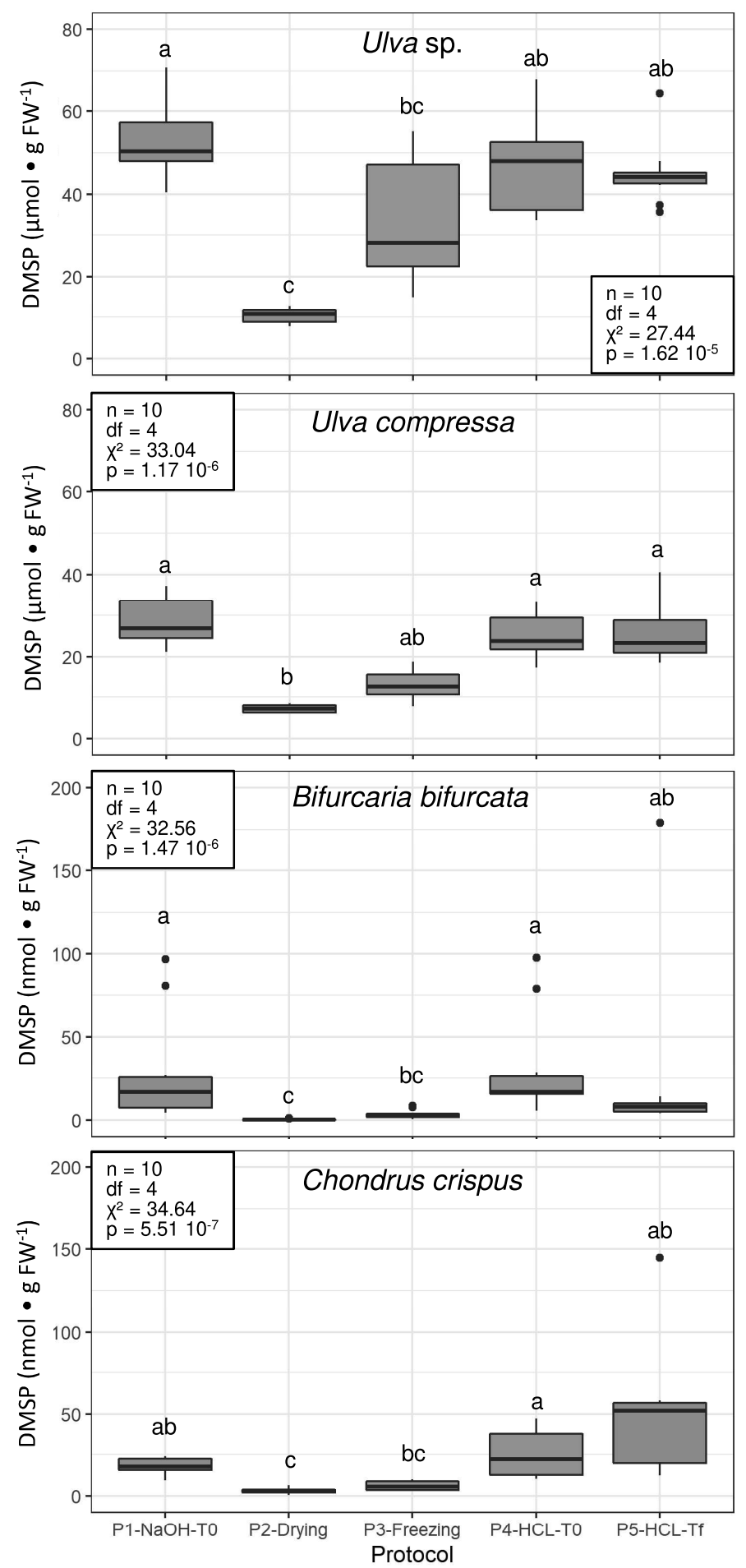

This article is protected by copyright. All rights reserved 